\title{
The Effectiveness of a DEAL-Based Intervention to Reduce Stress and Depression Symptoms
}

\author{
Muhamad Saiful Bahri Yusoff ${ }^{1}$, Mohd Jamil Yaacob ${ }^{2}$, Nyi Nyi Naing ${ }^{3}$, Abd Rahman Esa ${ }^{4}$ \\ ${ }^{1}$ Medical Education Department, ${ }^{2}$ Psychiatry Department, ${ }^{3}$ Biostatistics \& Research Methdology Unit, School \\ of Medical Sciences, Universiti Sains Malaysia, Kelantan, Malaysia. ${ }^{4}$ Faculty of Medical and Health Sciences, \\ Universiti Sultan Zainal Abidin, Terrenganu, Malaysia.
}

\section{ARTICLE INFO}

Received : :27/06/2014

Accepted : :02/12/2014

Published : :25/03/2015

\section{KEYWORD}

DEAL model

Stress

Anxiety

Depression

Medical students

Stress management

Mental health

\section{ABSTRACT}

Introduction: Many researchers have emphasized the importance of teaching stress management and self-care skills to medical students as they are vulnerable to develop psychological health problems. The researchers designed a 4-hour intervention based on the DEAL model to address these problems. This study aimed to determine outcomes of the DEAL-based intervention on medical students' stress, anxiety and depression symptoms. Methods: A randomized controlled trial study was conducted on 171 medical students. Their stress, anxiety and depression symptoms were measured by the 21-item Depression Anxiety Stress Scale at five intervals; at 2 weeks before the intervention, and at 1 week, 8 weeks, 16 weeks and 32 weeks after the intervention. The mixed model ANCOVA was applied to determine the effect of the intervention on the participants' psychological health at five intervals. Results: A total of 153 medical students (intervention $=73$ and control $=80$ ) completed this study. Results showed that the intervention group experienced significantly lower stress and depression symptoms than the control group. Although anxiety scores are consistently lower in the intervention group, no significant differences between groups were found. Conclusion: These results support the favourable outcomes of the intervention on psychological health of medical students. It is a promising intervention to be considered by medical schools as it consumes minimal amount of time, money, training and man power as well can be implemented easily.

(C) Medical Education Department, School of Medical Sciences, Universiti Sains Malaysia. All rights reserved.

CORRESPONDING AUTHOR: Dr. Muhamad Saiful Bahri Yusoff, Medical Education Department, School of Medical Sciences, Universiti Sains Malaysia, Kelantan, Malaysia. Email: msaiful_bahri@usm.my

\section{Introduction}

The visions of medical education are to produce academically competent, skillful and professional doctors to serve the people. The medical curriculum has been designed to achieve and accomplish these visions. However, some aspects of training may cause unwanted negative impacts on medical students' physical, emotional and mental health that inhibit these ambitions. Studies have reported that medical students' wellbeing deteriorate after students begin medical training and remains poor throughout the training (1-3), and the peak was during examination periods $(4,5)$. At individual level, psychological distress can contribute to poor academic achievement and personal developments (6-8). At professional level, 
studies have shown that psychological distress can lead to cynicism and subsequently may affects students' relationships with faculty, patients' care, feeling inadequate and unsatisfied with their career, and ultimately the culture of the medical profession (6-8). Thus, effective interventions are required to improve this situation.

Two systematic reviews revealed that interventions done on medical students had important positive outcomes on several important areas related to health; the outcomes ranged from positive feedback up to improvement of health biomarkers $(9,10)$. The reported positive outcomes were related to positive student feedback, improved psychological health, improved loneliness and mood disturbances, improved physiologic and immunologic health markers, improved quality of life, spirituality, and empathy, improved psychological states of mind, increased awareness about stress, its effects and management, and improved perceived ability to cope effectively and positively $(9,10)$. Despite these encouraging outcomes several drawbacks should be addressed in future research which are longer duration of follow up measurement on intended outcomes, more robust research method, including proper sample size calculation, random sampling of subjects, randomised allocation of subjects to intervention group and comparable control group, involvement of participants from different stages of medical training, and specify the theoretical basis of stress management was developed (9, 10). Likewise, there is lacking of evidence on the effectiveness of brief stress management interventions (i.e. intervention required less than two days) on the medical students (9). So far, only three available articles reported their effectiveness and all of them were nonrandomised controlled trial study (11-13). Apart from that, most of interventions required a substantial amount of time and faculty resources allocation in the academic schedule, so that make it difficult for medical schools to implement such programs $(9,14)$. Therefore, there is a need for an effective brief stress management intervention that uses little time and faculty resources allocation thus it can be implemented easily in the academic schedule. With this study, we aimed to overcome the drawbacks of the previous studies $(9,10)$ with regards to study subjects were selected from different phases of medical training, random sampling method was employed for selecting study subjects, proper sample size calculation was done and the intervention was designed based on a theoretical framework which was the DEAL model (15-18).

The DEAL model constitutes four components which are Detection of stressors, Evaluation of stressors, Action towards stressors and Learning from stressors through self-reflection (15-18). The detection of stressors is referred to how individuals receive and perceive demands (i.e. potential stressors) that interact with them. It is linked with the affective ability that involves in receiving and perceiving the potential stressors. It is alike a radar sensor to recognize potential threats that might harm them. This model postulates those who are aware, alert and had adequate knowledge about their stressors (i.e., problems) will be less bothered by the stressors and as a result will enable them to manage the problems more effective. Thus training and guiding students on detecting potential sources of stress will help them to deal with stress better. The evaluation of stressor is referred to a process involving identification, description, comprehension, analysis, synthesis and judgment on perceived stressors. It is linked with the cognitive ability because it requires mental abilities to performance all those processes. All these processes will enable individuals to specify and filter stressors that really bothering them, thus enable them to come out with appropriate solutions as responses towards the real stressors. From that notion, training and guiding students on proper evaluation of stressors will help them to develop positive way of thinking which help them to deal with stress effectively. The action towards stressors is referred to ways of individuals cope with stressful situations. It is linked with psychomotor ability because it requires coordination of emotion, mental and physical abilities to response towards the stressful situations. Thus training and guiding students on effective and positive ways of coping 
will enable them to handle stressful situations effectively and tactfully which eventually may lead to reduction of distress feelings. The learning from stressor through self-reflection is described as a process whereby stress management ability is acquired through one's awareness, experience and conscious effort that allow stressful situations to be handled effectively and efficiently in future. It acts as a self-evaluation tool that enables students to consolidate and mastery stress management skills based on their awareness, experience and conscious efforts. Thus training and guiding students to learning from stressors encountered will enable them to cope with the problems efficiently in future. Based on the DEAL model, four principles can be derived to design an effective stress management intervention that include 1) teach students to detect problems early and to have positive perception toward the problems; 2) teach students to appraise problems positively and appropriately; 3 ) teach students to cope with problems positively; and 4) teach students to learn from problems for future selfimprovement. In a nutshell, as individuals go through the intervention based on the DEAL model, they will acquire a greater degree of insight about their stress management ability through their awareness, experience and conscious effort that allow stressful situations to be handled effectively and efficiently. Eventually, they take more responsibility to continuously improve and develop their skills to in dealing with stressful transactions in better ways.

There were 3 questions to be answered by study which include; 1) is there any significant differences of stress symptoms between the intervention and control groups across the four time intervals post-intervention? 2) is there any significant differences of anxiety symptoms between the study groups across the four time intervals post-intervention? 3) is there any significant differences of depression symptoms between the study groups across the four time intervals post-intervention? Based on the literature reviews, we anticipated participants in the intervention group will experience lower stress, anxiety and depression symptoms than the control group across the four time intervals postintervention.

\section{Method}

\section{Study design}

A parallel randomized controlled trial was conducted. Ethical approval was obtained from the Human Research Ethics Committee Universiti Sains Malaysia Prior to the start.

\section{Participants}

This study was conducted at a Malaysian government medical school in the 2011/2012 academic session. The medical school adopted the SPICES curriculum design and it has 3 phases of medical training. In Phase I, students learn preclinical subjects in an integrated manner where teaching is done according to body systems. In Phase II this is revisited and students learn about the pathologies for each system. Students are also introduced to clinical clerking and physical examination. Phase III medical students undergo apprenticeship based on rotations in clinical departments such as obstetrics and gynecology, surgery and medicine.

\section{Interventions}

The intervention was developed based on the DEAL model (15-17). The intervention was divided into four main sections; the $1^{\text {st }}$ section was the introduction to the workshop and the information delivery on stress, stressors and coping strategies in relation to the medical students (section 1.0 ), the $2^{\text {nd }}$ section was the hands-on (section 2.0), the $3^{\text {rd }}$ section was the group work (section 3.0) and the $4^{\text {th }}$ section was the conclusion and feedback (section 4.0). Below were detail explanations of each section.

Section 1.0. The first part of this section was an introduction to the workshop with regards to the rationales and ways of this workshop would be conducted. It was begun by showing the WHO mental health video clip. Then it was followed by a brief presentation on how the workshop could help them to improve their stress 
management ability and reasons for them to participate actively by sharing their experience openly and honestly whenever necessary. The second part of this section was delivery of theoretical input related to stress, stressors and coping strategies in medical training context. It taught students about importance of stress management, concepts and models of stress, relationships between stress, stressors and coping strategies, and impacts of bad stress on one's wellbeing. (75 minutes were allocated)

Section 2.0. The first part of this section was filling in questionnaires. Participants were guided to fill in the 12-item General Health Questionnaire (GHQ-12), the 20-item Medical Student Stressor Questionnaire (MSSQ-20) and the 30-item Brief Coping Oriented Problem Experienced (Brief COPE-30) completely. The GHQ-12 was used to measure stress level (1921), the MSSQ-20 was used to identify potential sources of stress $(22,23)$, and the Brief COPE30 was used to recognized coping strategies (24, 25). The participants were told to answer all questions honestly because the results obtained would be more valid, reliable and therefore reflect their stress level, sources of stress, and coping strategies. This section aimed to instill awareness among the participants about their own stress level, sources of stress, and coping strategies so that they will realize their strengths, weaknesses and opportunities for improvement. The second part of this section was interpretation and discussion of the results of GHQ-12, MSSQ20 and Brief COPE-30 within small groups and later between the small groups. Each participant was given a stress-stressor-coping diagram (Appendix 1) as a tool to facilitate interpretation and discussion of the results. Participants were asked to fill in the boxes (i.e. GHQ, MSSQ and Brief COPE boxes) provided in the diagram. The interpretations of the scores were shown to the participants and they were asked to volunteer to share their results with other participants as a trigger for discussion. Then, based on the MSSQ, each of group members listed out their personal top five stressors that they perceived as causing the highest pressure on them and followed by discussion with their group members to draw a list of the top five stressor for their group. Each group was asked to share their group's top five stressors with the rest of groups. Through this activity participants should be able to get a clear message that everyone has their own problems (stressors) in which the problems may be common and may be unique to each other; however how persons perceive the problems may influence their distress feelings, if the persons perceived the problems positively then they may feel less distress and vice versa. After these activities, it was followed by discussion on coping strategies based on the Brief COPE results. This section aimed to guide them to appraise and reflect on their own stress level, sources of stress, and coping strategies so that later could help them to develop healthy mindset, positive thinking and adaptive coping strategies towards stressful events. The third part of this section was allocated to discussion on ways of handling stress based on the DEAL model (15). This section aimed to recap and consolidate their understanding on applications of the early detection of potential problems, proper appraisal about the problems, positive ways to react or response toward the problems, and learning from the problems through self-evaluation to improve their capability to deal with the problems positively and appropriately. Eventually, based on the DEAL model, they will take more responsibility to continually improve their ways of dealing with stressful transactions effectively. (85 minutes were allocated)

Section 3.0. This section was devoted for group work on two scenarios provided in the form of video clips. The first video clip was about a women living with a mentally ill husband and the second video clip was about a quarrel between a doctor and a nurse. The participants were requested to discuss in small groups about lessons they gained and learnt from the video clips. Following that, each group was requested to share what they had gained and learnt from the videos with the rest of groups. In addition, they were also requested to share their insight about what would they do if they were in these situations. This section aimed to consolidate understanding about dealing with stress using the DEAL model through intra-group and intergroup discussion as well as to promote and 
facilitate self-reflection practice based on the scenarios. (60 minutes were allocated)

Section 4.0. This session was allocated for feedback and conclusion. The participants were requested to share voluntarily about: 1 ) what are the new insight or ideas have they learned and gained as result of attending this workshop? 2) What are the things they hope to apply from what they have learnt and gained from this workshop when they return to their duties? This section aimed to recap the key messages gained from this intervention, to provide opportunity to the participants to share their thoughts and experience with others, and to provide feedback for any misconception on relevant topics. (20 minutes were allocated)

Participants completed the intervention within 240 minutes (4 hours) over a half-day.

\section{Outcomes}

Three main outcomes were measured: stress, anxiety and depression. Stress, anxiety and depression symptoms were measured by the 21item Depression Anxiety Stress Scale (DASS21) (26).

The DASS was developed for people aged 17 and older however may be suitable for younger age (27). It is used to assess the severity of core symptoms of depression, anxiety and tension (or stress) over the previous week; in general it provides a broad spectrum measure of psychological distress, indicating the severity and frequency of symptoms (26). The DASS-21 is a self-reporting instrument with a total of 21 items. It has three main scales which are depression (DASS-D), anxiety (DASS-A) and stress (DASS-S); each scale has 7 items. Each item uses four-point response scale and separate depression, anxiety and stress scores are calculated by summing item scores. The scale scores of DASS-21 must be multiplied by two to stimulate the full-scale version; the scores ranged from 0 to 42. A high score indicates a high level of the symptoms (26). The reliability coefficients of depression, anxiety and stress scales range from 0.81 to 0.97 , and the three subscales showed discriminative ability to differentiate between psychiatric patient and non-psychiatric patients (27). It was used in this study due to it requires less time to administer; furthermore, studies showed it is superior and more consistent compared to the full-scale version (27). The correlation (i.e. indicating convergent and discriminant validity) between the DASS-21 and other psychological health measurements were well established (27).

Data was collected from the study groups at five different intervals; the baseline measurement were measured 2 weeks before the intervention (Time 1), at 1 week (Time 2), 8 weeks (Time 3), 16 weeks (Time 4) and 32 weeks (Time 5) after the intervention. The rationale of multiple point measurements post intervention was to capture the psychological state of medical students throughout different stages of medical training so that more accurate results could be obtained. Socio-demographic profiles (refer to Table 1) were obtained through a form.

\section{Sample size}

Sample size was calculated by Sample Size Precision Calculator (SPCC) software (28) based on preliminary data (12). The calculated sample size after adjustment of 30\% dropout rate was 50 subjects per study group. Considering this study randomly invited study subjects through postal invitations, therefore the sample size was readjusted to address the non-response rate to the invitation which was estimated up to $80 \%$ (29, 30). After the readjustment, the final sample size per group was 250 subjects across years of study; thus the total of study subjects was 500 .

\section{Sampling and randomization methods}

A total of 100 students were invited from each year of study to participate in this study through the stratified random sampling method. The study subjects were stratified by sex (40\% male and $60 \%$ female) and race (60\% Malay and $40 \%$ non-Malay) based on the prevalence of psychological distress reported by a previous study (31). Name lists of medical students from first to fifth year were obtained from the 
academic office and each student was given a unique code. Random selection was performed by Statistical Package for Social Sciences (SPSS) version 18 (32). The selected study subjects were invited to attend a 3-hour briefing session regarding the study protocol as well as signing an informed consent form. Study subjects who signed the informed consent form were then randomly allocated into the intervention and control groups through draw lots. The intervention group underwent a 4-hour intervention that was conducted in the workshop form, while the control did not undergo any intervention (in the waiting list).

\section{Blinding}

To ensure researchers were blinded during analysis, data were collected and entered into a data sheet by a research assistant and study subjects were assigned with a unique code throughout the study.

\section{Statistical analysis}

The collected data was analyzed using SPSS version 18. Data were checked for data entry errors and missing values, explored and cleaned. The investigators used alpha $(\alpha)$ at 0.05 and confidence interval of 95\%. Descriptive statistics were applied to calculate frequency, percentage, mean and standard deviation for the variables. The chi-square test was applied to test difference of categorical outcomes between two categories of independent variable. The mixed model analysis of covariance (ANCOVA) was applied to test the different of mean stress, anxiety and depression scores between two study groups measured repeatedly at four time intervals postintervention (33). The baseline scores were considered as covariates in this analysis. The multivariate statistics were used for analysis due to it does not require sphericity assumption (33). Three assumptions for the mixed model ANCOVA were checked: 1) normality of residual, 2) homogeneity of variances, and 3) linear relationships between numerical covariates and dependent outcomes. Partial eta squared was used to estimate effect size. Using the commonly used guidelines proposed by Cohen (1988, pp.284-7): $0.01=$ small effect, $0.06=$ moderate effect, 0.14 = large effect (34).

\section{Result}

Table 1: Profiles of participants successfully completed this study.

\begin{tabular}{|c|c|c|c|c|c|}
\hline \multirow[t]{2}{*}{ Variable } & \multicolumn{3}{|c|}{$\begin{array}{l}\text { Study group, } \\
\text { frequency (\%) }\end{array}$} & \multirow[t]{2}{*}{$X^{2}$-statistics } & \multirow[t]{2}{*}{ P-value* } \\
\hline & Intervention & Control & Total & & \\
\hline $\begin{array}{l}\text { Sex } \\
\text { Male } \\
\text { Female }\end{array}$ & $\begin{array}{l}25(34.2) \\
48(65.8)\end{array}$ & $\begin{array}{l}29(36.3) \\
51(63.8)\end{array}$ & $\begin{array}{l}54(35.3) \\
99(64.7)\end{array}$ & $0.067^{1}$ & 0.798 \\
\hline $\begin{array}{l}\text { Race } \\
\text { Malay } \\
\text { Non-Malay }\end{array}$ & $\begin{array}{l}58(79.5) \\
15(20.5)\end{array}$ & $\begin{array}{l}61(76.3) \\
19(23.7)\end{array}$ & $\begin{array}{c}119(77.9) \\
34(22.1)\end{array}$ & $0.226^{1}$ & 0.634 \\
\hline $\begin{array}{l}\text { Religion } \\
\text { Muslim } \\
\text { Non-Muslim }\end{array}$ & $\begin{array}{l}58(79.5) \\
15(20.5)\end{array}$ & $\begin{array}{l}61(76.3) \\
19(23.7)\end{array}$ & $\begin{array}{c}119(77.9) \\
34(22.1)\end{array}$ & $0.226^{1}$ & 0.634 \\
\hline $\begin{array}{l}\text { Year of study } \\
\text { First } \\
\text { Second } \\
\text { Third } \\
\text { Fourth } \\
\text { Fifth } \\
\end{array}$ & $\begin{array}{c}32(43.8) \\
13(17.8) \\
14(19.2) \\
5(06.9) \\
9(12.3) \\
\end{array}$ & $\begin{array}{c}41(51.3) \\
12(15.0) \\
14(17.5) \\
5(06.3) \\
8(10.0) \\
\end{array}$ & $\begin{array}{l}73(47.7) \\
25(16.4) \\
28(18.3) \\
10(06.5) \\
17(11.1) \\
\end{array}$ & $0.890^{1}$ & 0.926 \\
\hline $\begin{array}{l}\text { Entry qualification } \\
\text { Matriculation } \\
\text { Non-Matriculation }\end{array}$ & $\begin{array}{l}60(82.2) \\
13(17.8)\end{array}$ & $\begin{array}{l}64(80.0) \\
16(20.0)\end{array}$ & $\begin{array}{c}124(81.0) \\
29(19.0)\end{array}$ & $0.119^{1}$ & 0.730 \\
\hline $\begin{array}{l}\text { Repeater status } \\
\text { No } \\
\text { Yes } \\
\end{array}$ & $\begin{array}{c}64(87.7) \\
9(12.3) \\
\end{array}$ & $\begin{array}{c}71(88.7) \\
9(11.3) \\
\end{array}$ & $\begin{array}{c}135(88.2) \\
18(11.8)\end{array}$ & $0.043^{1}$ & 0.836 \\
\hline
\end{tabular}

*Pearson Chi-square test

${ }^{1}$ Expected count less than 5 was $10 \%$ 
The overall participation rate was 34\% (171 out of 500). Out of 171 medical students who consented to participate in this study, 153 successfully completed this study; 73 in intervention group and 80 in control group. The total dropout was approximately $11 \%$ (18 out of 171); most of them provided no reason for withdrawal from the study. Demographic profiles of the participants were summarized in table 1.
Pearson chi-square test showed no significant differences of the demographic profiles between the study groups (table 1). These results suggested that randomization successfully distributed study subjects into two homogenous groups.

Table 2: Comparison of outcomes’ mean scores between the study groups at baseline.

\begin{tabular}{|l|l|l|l|l|}
\hline \multirow{2}{*}{ Outcome Variable } & \multicolumn{2}{|c|}{ Study group } & \multirow{2}{*}{ t-statistic } & \multirow{2}{*}{$\boldsymbol{p}$-value } \\
\cline { 2 - 5 } & Intervention, mean (SD) & Control, mean (SD) & & 0.77 \\
\hline Stress & $12.36(6.59)$ & $11.58(5.97)$ & 0.443 \\
\hline Anxiety & $11.15(7.56)$ & $9.93(6.44)$ & 1.08 & 0.281 \\
\hline Depression & $6.60(6.08)$ & $4.85(5.26)$ & 1.91 & 0.058 \\
\hline
\end{tabular}

Independent-t test was applied. Significant level was set at 0.05 . Levene's test was not significant for all outcome variables.

Independent-t test was performed to compare the baseline scores of measured outcomes between the two study groups. Although the psychological symptoms of the intervention group higher than the control group, no significant differences were found (table 2). It suggested that the two study groups' psychological status prior to the study were homogenous.

Table 3: Adjusted mean stress, anxiety and depression scores within the study groups at different time intervals.

\begin{tabular}{|c|c|c|c|c|c|}
\hline \multirow{2}{*}{$\begin{array}{l}\text { Psychological } \\
\text { parameter }\end{array}$} & \multirow{2}{*}{$\begin{array}{l}\text { Post } \\
\text { intervention }\end{array}$} & \multicolumn{2}{|r|}{ Intervention group } & \multicolumn{2}{|r|}{ Control group } \\
\hline & & $\mathbf{n}$ & AM (95\% CI; lower, upper) & $\mathrm{n}$ & AM (95\% CI; lower, upper) \\
\hline \multirow[t]{4}{*}{ Stress $^{1}$} & 1 week & 73 & $8.82(7.52,10.12)$ & 80 & $11.82(10.58,13.07)$ \\
\hline & 8 week & 73 & $8.93(7.37,10.49)$ & 80 & $11.50(10.01,12.99)$ \\
\hline & 16 week & 73 & $8.80(7.04,10.56)$ & 80 & $12.29(10.61,13.97)$ \\
\hline & 32 week & 73 & $9.69(7.90,11.47)$ & 80 & $11.74(10.03,13.44)$ \\
\hline \multirow[t]{4}{*}{ Anxiety $^{2}$} & 1 week & 73 & $6.98(5.96,8.00)$ & 80 & $8.80(7.83,9.78)$ \\
\hline & 8 week & 73 & $7.29(5.96,8.62)$ & 80 & $8.24(6.97,9.51)$ \\
\hline & 16 week & 73 & $7.75(6.11,9.40)$ & 80 & $9.82(8.26,11.39)$ \\
\hline & 32 week & 73 & $7.57(5.92,9.22)$ & 80 & $8.77(7.19,10.34)$ \\
\hline \multirow[t]{4}{*}{ Depression $^{3}$} & 1 week & 73 & $4.77(3.72,5.82)$ & 80 & $6.20(5.20,7.20)$ \\
\hline & 8 week & 73 & $4.42(3.11,5.74)$ & 80 & $7.69(6.44,8.94)$ \\
\hline & 16 week & 73 & $4.99(3.57,6.40)$ & 80 & $7.57(6.22,8.92)$ \\
\hline & 32 week & 73 & $5.61(4.14,7.09)$ & 80 & $6.80(5.40,8.21)$ \\
\hline
\end{tabular}

The mixed model ANCOVA was applied.

Covariates: baseline stress ${ }^{1}$, anxiety ${ }^{2}$ and depression ${ }^{3}$ scores.

$\mathrm{AM}=$ Adjusted mean; $\mathrm{SD}=$ standard deviation; $\mathrm{CI}$ = confidence interval

Assumptions were checked: 1) Normality of residual was fulfilled, 2) Homogeneity of variances was fulfilled, 3) Linear relationships between numerical covariates and dependent outcomes were fulfilled. 


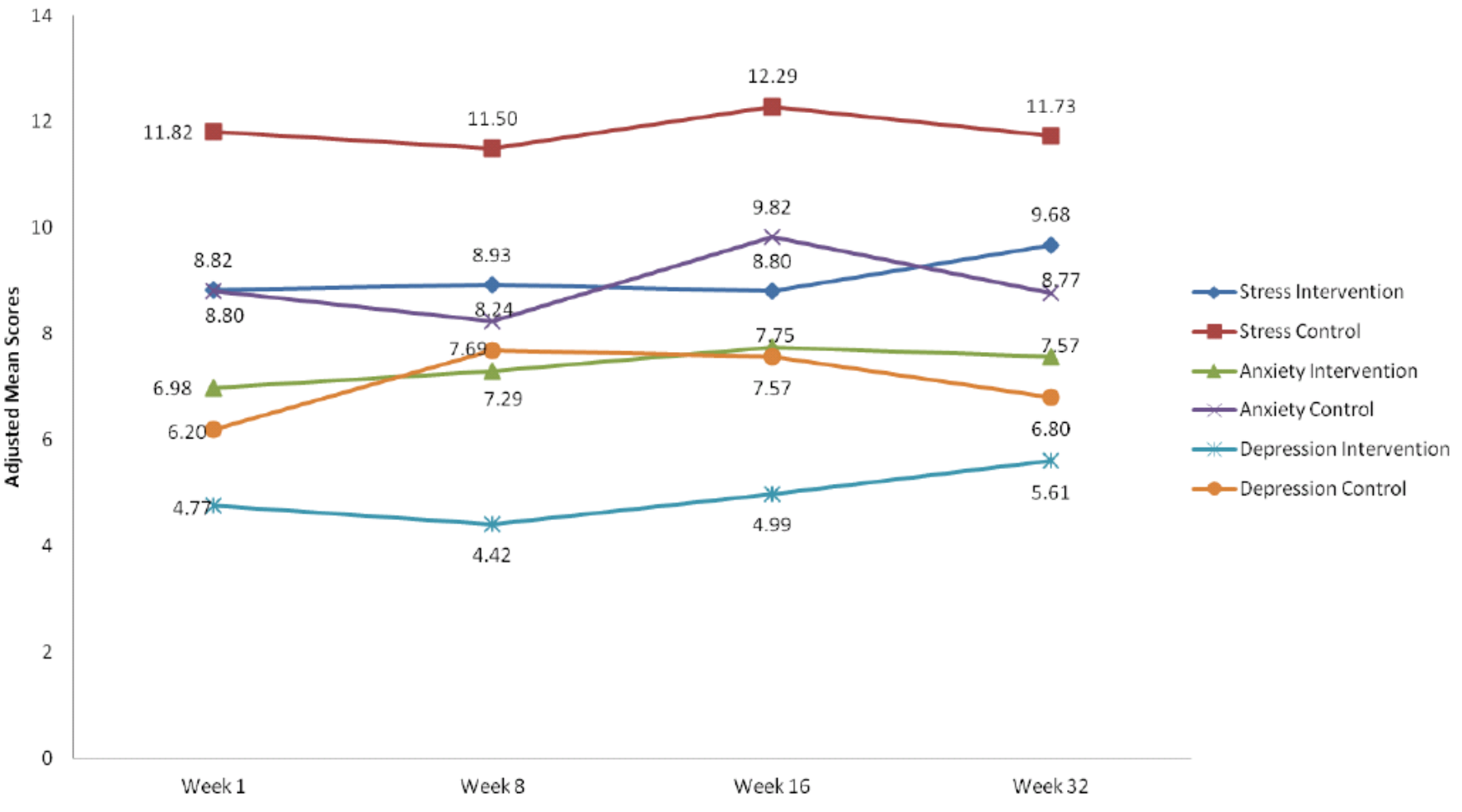

Figure 1: Adjusted mean scores of stress, anxiety and depression by the study groups at different time intervals after controlling the covariates (i.e. baseline measurement).

Descriptive analysis of adjusted mean scores of stress, anxiety and depression symptoms between the study groups across intervals were summarized in the table 3 and illustrated in the figure 1. Generally, the intervention group has lower psychological symptoms than the control group across the four time intervals postintervention.

Stress. The mixed model ANCOVA (table 3) shows no significant interaction between study groups and time, Wilk's Lambda $=0.99, \mathrm{~F}$ (3, $148)=0.48, p=0.70$, partial eta squared $=0.10$. There was no significant main effect for time, Wilk's Lambda $=1.00, \mathrm{~F}(3,148)=0.15, \mathrm{p}=$ 0.93 , partial eta squared $=0.003$. The main effect comparing the two study groups was significant, $\mathrm{F}(1,150)=9.93, \mathrm{p}=0.002$, partial eta squared $=$ 0.06 , suggesting significant difference in the effectiveness of the study groups with a moderate effect size. This result suggests the intervention group has significantly lower stress symptoms than the control group across the four time intervals post-intervention.

Anxiety. The mixed model ANCOVA (table 3) shows no significant interaction between study groups and time, Wilk's Lambda $=0.49, \mathrm{~F}$ (3, $148)=0.49, \mathrm{p}=0.69$, partial eta squared $=$ 0.010 . There was no significant main effect for time, Wilk's Lambda $=0.96, \mathrm{~F}(3,148)=2.14, \mathrm{p}$ $=0.098$, partial eta squared $=0.042$. The main effect comparing the two study groups was significant, $F(1,150)=3.76, p=0.055$, partial eta squared $=0.024$, suggesting no difference in the effectiveness of the study groups. This result suggests the two study groups were equally anxiety across the four time intervals postintervention.

Depression. The mixed model ANCOVA (table 3) shows no significant interaction between study groups and time, Wilk's Lambda $=0.96, \mathrm{~F}$ $(3,148)=2.13, p=0.10$, partial eta squared $=$ 
0.041. There was no significant main effect for time, Wilk's Lambda $=0.95, \mathrm{~F}(3,148)=2.54, \mathrm{p}$ $=0.06$, partial eta squared $=0.049$. The main effect comparing the two study groups was significant, $\mathrm{F}(1,150)=8.93, \mathrm{p}=0.003$, partial eta squared $=0.06$, suggesting significant difference in the effectiveness of the study groups with a moderate effect size. This result suggests the intervention group has significantly lower depression symptoms than the control group across the four time intervals postintervention.

Table 4: Post-hoc power of study analysis based on mean scores of the measured outcomes.

\begin{tabular}{|l|l|l|l|l|}
\hline Outcomes & Adjusted mean & $\begin{array}{l}\text { Standard } \\
\text { deviation }\end{array}$ & $\begin{array}{l}\text { Mean correlation } \\
\text { (r1) }\end{array}$ & Power of study \\
\hline $\begin{array}{c}\text { Stress } \\
\text { Mean1 }\end{array}$ & 9.25 & 5.56 & 0.60 & 0.996 \\
Mean2 & 11.67 & 5.55 & 0.59 & 0.684 \\
\hline $\begin{array}{c}\text { Anxiety } \\
\text { Mean1 }\end{array}$ & 7.61 & 4.79 & 4.79 & \\
Mean2 & 8.72 & 4.41 & 0.53 & 0.989 \\
\hline $\begin{array}{c}\text { Depression } \\
\text { Mean1 } \\
\text { Mean2 }\end{array}$ & 5.10 & 4.40 & & \\
\hline
\end{tabular}

The post-hoc power of study was calculated by Stata 9 based on the power of study command for the repeated measured: sampsi mean1 mean2, sd1(value) sd2(value) method(all) pre(1) post(4) r1(value) n1(73) n2(80)

Pre measurement (pre) was 1 time and post Measurement (post) was 4 times. $n 1=73$, n2 = 80, mean1 = mean score of intervention group, mean 2 = mean score of control group. $\mathrm{sd} 1=$ standard deviation of mean 1 and sd2 = standard deviation of mean2.

Post-hoc power of study analysis found that all outcomes except anxiety have more than sufficient power to detect differences between the study groups (table 4). These results suggested that the findings obtained for stress and depression outcomes are true reflection of the impacts of the intervention on the studied population. In contrast, the results obtained for anxiety outcomes should be interpreted with caution because it might not be a true reflection of the intervention's impacts. Therefore more sample size is required to verify the result related to anxiety symptoms.

\section{Discussion}

In general, our empirical results demonstrated that participation in the 4-hour stress management intervention can effectively improve stress and depression symptoms. Despite, results failed to demonstrate its effectiveness to improve anxiety symptoms. Nonetheless, the intervention group was consistently experience lower anxiety symptoms that the control group after the intervention (table 3 and figure 1). These favourable findings in line with previous studies found the intervention significantly improved psychological distress symptoms experienced by medical students (11, 12). Likewise, these finding conformed to other studies showing that special stress management interventions helped to improve psychological health of medical students $(9,10)$. It is interesting to highlight that despite higher level of stress, anxiety and depression symptoms experienced by the intervention group than those in the control group at the baseline measurement, the intervention group consistently experienced lower stress, anxiety and depressions symptoms than the control group at post-intervention measurements (table 3 and figure 1). These results suggested the 4-hour intervention significantly improved psychological distress among medical students. Two systematic reviews revealed that other special interventions 
required at least 3 weeks of implementation to produce similar results $(9,10)$.

Our empirical data showed the intervention group had significant lower stress symptoms that the control group. Similarly, the effect size value for stress symptoms was moderate, suggesting a substantial effect of the brief intervention on stress symptoms of its participants. This result supports the beneficial outcome of the brief intervention and consistent with the literature showing that special programs designed for medical students may impart beneficial effects on their stress symptoms $(9,10)$. Two RCT studies reported similar effect on stress symptoms of medical students $(35,36)$. The calculated Cohen effect size (i.e. effect size was considered as small if less than 0.2 , moderate if in between 0.2 and 0.8 , and large if more than $0.8(37,38))$ for first study (i.e. self-hypnosis training) (36) was large and for the second study (i.e. stress management training course) (35) was moderate. The first study employed its intervention by a clinical psychologist over 6 weeks (36) and the second study employed its intervention by two psychiatrist over one semester. Comparing the effect size found in this study with the two RCT studies, it appear that the intervention in this study had weaker effect size compare to the first study (36) and equal effect size to the second study (35) on the stress symptoms. One lesson learnt is that shortduration of stress intervention designed based on a well-defined theoretical framework can provide similar benefits of long-duration interventions on the stress symptoms of medical students. Thus, an effective intervention should produce beneficial outcomes within an affordable duration of time so that it can be easily integrated in the time table and accepted by the students. Likewise, an innovative intervention must demonstrate good ideas, demonstrable improvement, planned implementation, and supported by evidence (39). Apart from that, it should be highlighted each study used different psychological health measurements therefore direct comparison would not reflect the real different of the intervention effects on medical students' stress symptoms. Despite the differences, this study provides evidence supporting the favourable outcome of the 4-hour stress management intervention on medical students' stress symptoms. In addition, based on literatures $(9,10)$ and this study finding, it clearly indicates that special interventions provide beneficial effects on psychological health of medical students. Considering the favourable outcome of the 4-hour intervention on medical students' stress symptoms, medical schools are recommended to implement the brief intervention as a prevention measure.

Studies have shown that the prevalence of depression among medical students is escalating throughout the medical training $(3,8,40,41)$ and its unfavourable consequences on the medical students' personal and professional development are well documented $(6-8,42)$. Therefore preventing medical students from developing severe depression symptoms would provide great implications on their personal and professional development as future medical doctors. Our empirical data showed that the intervention group had significant lower depression symptoms than the control group (table 3 and figure 1). The effect size was moderate, indicating a substantial effect of the brief intervention on depression symptoms of its participants. Three RCT studies reported similar effect on medical students' depression symptoms $(43,44)$. The calculated Cohen effect size of two studies (i.e. support group for hypnotic and relaxation exercise, and a brief-intervention) (44, 45) was small and for another study (i.e. the mindfulness based stress management) (43) was moderate. The first study employed the intervention by a clinical psychologist for unknown duration as it was not specifically mentioned (44) and the second study employed the intervention by clinical psychologists over 7 weeks (43). In comparison with two RCT studies $(43,44)$, the brief intervention in this study showed similar or more benefit on medical students' depression symptoms. Additionally, similar result was also noted in a previous study (45). Interestingly, despite short duration in nature, the DEAL-based intervention produced similar or better outcomes as of other interventions $(43,44)$ on medical students' depression symptoms. Looking at this evidence, 
it could be said that this intervention is a promising stress management intervention that should be introduced by medical schools due to the fact that it is easy to be implemented, consumes minimal amount of time, requires nonpsychiatrists or non-psychologist as facilitators to implement it and requires less amount of money as well as facility. It is worthy to highlight that medical students who experienced less depression symptoms may attain greater personal and professional accomplishment (6-8, 42).

This study failed to demonstrate a significant improvement of the medical students' anxiety symptoms in the intervention group as compared to the control group (Table 3). Although no differences were found, relatively the intervention group experienced lower anxiety symptoms than the control group. Likewise, the effect size was very small, it is therefore not surprising that it did not reach statistical significant. There were three RCT studies showed beneficial effects on medical students' anxiety symptoms which include the support group for hypnotic and relaxation (moderate Cohen effect size) (44), the self-hypnosis training (moderate Cohen effect size) (35) and the mindfulness based stress reduction (moderate Cohen effect size) (43). The effect size recorded by our intervention was weaker than the three RCT studies (35, 43, 44). These facts are very interesting because it seems that to reduce anxiety more effectively some forms of physical activity should be included as part of the stress management intervention. This is consistent with findings of a systematic review mentioning that regular physical activity may play a vital role in the management of anxiety symptoms, and the beneficial effects appear to equal meditation or relaxation (46). Perhaps this is a reason that leads to ineffectiveness of our brief intervention to improve anxiety symptoms of the participants. From that notion, our intervention may produce greater effect on anxiety symptoms if training on proper relaxation technique is incorporated Apart from that, it is worth highlighting that the results might not hold a true reflection of the intervention effect since the post-hoc power of study analysis showed that anxiety outcome was under power which was less than 0.8 (table 4). Perhaps, future study involving multiple medical schools would be able to recruit more study subjects to improve the power of study therefore it will verify this present finding. Nevertheless, despite statistically insignificant, yet it provides evidence supporting the potential beneficial effects of the intervention on the students' anxiety symptoms.

In a nutshell, this study showed that the brief stress management intervention effectively improved psychological wellbeing of medical students. The intervention is considered as a preventive intervention due to the participants were not selected based on any criteria related to psychological health status (47). In addition, the magnitude of the intervention effect is comparable to the effects produced by the mindfulness based stress reduction on medical students' psychological health (43). Apart from that, this study employed better research approach than the previous RCT studies $(35,36$, $43,44,48-50$ ) with regard to 1) study subjects were selected from different phases of medical training, 2) random sampling method was applied, 3) proper sample size calculation was done and 4) the module was designed based on a theoretical framework which was the DEAL model $(16,18)$. Thus, a comparison study should be conducted to look for which intervention provides greater impacts on psychological wellbeing of medical students; this could lead to customized stress management intervention.

There were several limitations that should be considered for future improvement. First, this study was confined to one medical school that limiting the generalisability of this finding to other medical schools. Second, majority of the participants were from first year medical students; therefore the results might not really reflect the 'true' effect of the intervention on medical students from different phases of medical training. Third, the number of sample size was inadequate thus lead to under power of study to elicit the true effect of the intervention on the anxiety symptoms of medical students. Fourth, the study was conducted purely quantitative therefore it provided very limited 
data for exploring the participants' feedback about the real benefits they have gained as a result of attended the intervention. Fifth, this study only used one psychological health measurement instrument to measure psychological outcomes of the participants; therefore it might not really measure the multidimensional of psychological wellbeing. Sixth, about $34 \%$ of eligible participants participated in this study thus it could be due to a self-selection bias in terms of the participants' levels of stress, anxiety and depression. For instance, only those students who relatively little stress may have participated thus may influence the effective of the training and on the study outcomes. Perhaps, future study should include positive control group to address this limitation. Seventh, the control group did not receive any intervention, therefore it appears that the intervention group was compared with 'nothing'. Therefore, conclusion about its effectiveness than other types of intervention could not be made. Nevertheless, it should be noted that the control group was purposely not assigned to any types of intervention because of to resemble the actual condition of general medical students' psychological health condition during medical training. In addition, this study did not include any objective to compare with other types of intervention. Perhaps, this could be done in future study. Last but not least, this study only explored the psychological aspects which mostly depend on the participants' perception on how they felt during the measurement period, therefore it might compromise the accuracy of the result due to the rater judgment errors which mostly reported as over-rating, imprecise interpretation and often failed to document serious deficit (51). Considering these limitations, the results should be used and interpreted within its context. Even more, any attempts to generalize it to other educational settings should be done within these limitations.

Despite the limitations mentioned above, this study has several strengths to support the validity and credentials of the results obtained. First, the study used the highest level of study which was a randomized controlled trial that is a gold standard to elicit the treatment effects of an intervention on measured outcomes. Second, this study used a sampling method that has the least bias which was the stratified random sampling method. Third, the control group was comparable to the intervention group; therefore comparisons could be made with the least bias. Fourth, a proper sample size calculation was performed prior to the study start; therefore the different of measured outcomes can be tested at appropriate power of study. Fifth, the researcher was blinded from the participants' detail during the data analysis, thus the analysis was performed under the least bias situation. Sixth, this study measured outcomes repeatedly before and after the intervention over one year period for several times; thus, the effect of the intervention over time could be captured accurately. Finally, this study measured the main common outcomes of psychological dimension as measured by previous studies which was stress, anxiety and depression symptoms $(9,10$, $47,52,53)$; therefore comparison can be done with the previous studies.

Based on the findings, limitations and strengths, several recommendations are proposed. First, this study should be replicated at other medical schools to verify the credentials of the intervention effects in other educational settings. Second, multiple psychological and physiological measurement tools should be used to measure the multi-dimensional of psychological wellbeing. Third, the qualitative research methods such as focus group discussion and in-depth interview should be included in future study to explore the participants' view about the impacts of the intervention on their daily practice. Fourth, sample size required to test anxiety outcomes should be recalculated in future study to ensure adequate power of study to detect the effects of the intervention. Lastly, future study should be done to test whether the intervention effect is 'operator-dependent'. Apart from that, this intervention is recommended to be implemented and adopted by medical schools as a preventive intervention for their medical students. Even more, this intervention requires very minimal duration of time which is about half-day, non-specialist facilitators to conduct the intervention, low cost, low tech facilities, 
module is easily understood and implemented, no special training and it is now freely downloadable at MedEdPORTAL (15).

\section{Conclusion}

The results support the favorable effects of the brief stress management intervention on psychological wellbeing of medical students. Likewise, our results are consistent with other studies demonstrating that special intervention programs help the students deal with stress effectively. It is a promising intervention to be adopted by medical schools as it consumes minimal amount of time, money, training and man power as well as simple to be implemented. The DEAL model is a promising educational strategy to be adopted as a basis for developing stress reduction intervention. Continued research is required at different medical schools to verify the impacts of the intervention and the DEAL model on medical students' psychological wellbeing.

\section{Acknowledgement}

Our greatest appreciation to Universiti Sains Malaysia for the financial support via Research University Grant (1001/PPSP/812086). Last but not least our deepest gratitude to all medical students who willingly participated in this study.

\section{Reference}

1. Guthrie EA, Black D, Bagalkote H, Shaw C, Campbell M, Creed F. Psychological stress and burnout in medical students: a fiveyear prospective longitudinal study. Journal of the Royal Society of Medicine. 1998;91(5):23743.

2. Niemi PM, Vainiomaki PT. Medical students' distress-quality, continuity and gender differences during a six-year medical programme. Medical teacher. 2006;28(2):13641.

3. Yusoff MSB, Abdul Rahim AF, Baba AA, Ismail SB, Mat Pa MN, Esa AR. The impact of medical education on psychological health of students: A cohort study. Psychology, Health \& Medicine [serial on the Internet]. 2012.

4. Yusoff MSB, Liew YY, Ling HW, Tan CS, Loke HM, Lim XB, et al. A study on stress, stressors and coping strategies among Malaysian medical students. International Journal of Students' Research. 2011;1(2):45-50.

5. Yusoff MSB. Impact of summative assessment on first year medical students' mental health. International Medical Journal. 2011;18(3):172-5.

6. Dyrbye LN, Thomas MR, Shanafelt TD. Medical student distress: causes, consequences, and proposed solutions. Mayo Clinic Proc. 2005;80(12):1613-22.

7. Dyrbye LN, Thomas MR, Massie F, Power DV, Eacker A, Harper W, et al. Burnout and suicidal ideation among US medical students. Annals of internal medicine. 2008;149(5):334-41.

8. Dyrbye LN, Thomas MR, Shanafelt TD. Systematic review of depression, anxiety, and other indicators of psychological distress among US and Canadian medical students. Academic Medicine. 2006;81(4):354-73.

9. Yusoff MSB, Esa AR. Stress management for medical students: A systematic review. In: Lopez-Varela MA, editor. Social Sciences and Cultural Studies - Issues of Language, Public Opinion, Education and Welfare. Croatia: InTech; 2012.

10. Shapiro SL, Shapiro DE, Schwartz GER. Stress management in medical education: a review of the literature. Academic Medicine. 2000;75(7):748.

11. Yusoff MSB. Effects of a brief stress reduction intervention on medical students' depression, anxiety and stress level during stressful period. Asean Journal of Psychiatry. 2011;12(1).

12. Yusoff MSB, Rahim AFA. The impact of medical students well-being workshop on medical students' stress level: A preliminary finding. ASEAN Journal of Psychiatry. 2010;11(1).

13. Zeitlin D, Keller SE, Shiflett SC, Schleifer SJ, Bartlett JA. Immunological effects of massage therapy during academic stress. Psychosomatic Medicine. 2000;62(1):83-4.

14. McGrady A, Brennan J, Lynch D, Whearty K. A Wellness Program for First Year Medical Students. Applied Psychophysiology and Biofeedback. 2012;37(6):1-8.

15. Yusoff MSB, Esa AR. The Medical Student Wellbeing Workshop. MedEdPORTAL [serial on the Internet]. 2012: Available from: http://www.mededportal.org/publication/9241.

16. Yusoff MSB, Yaacob MJ, Naing NN, Esa AR. An educational strategy to teaching stress management skills in medical education: 
the DEAL model. International Medical Journal. 2013;20(2):1-11.

17. Yusoff MSB, Esa AR. Medical Student Wellbeing Workshop: A stress management programme for medical students. Saarbrucken, Germany: VDM Verlag Dr Muller GmbH \& Co. KG; 2011.

18. Yusoff MSB, Yaacob MJ, Naing NN, Esa AR. A conceptual framework of stress management intervention for medical students. Education in Medicine Journal. in press;5(3).

19. Goldberg D. Manual of the General Health Questionnaire. Windsor. Berks:: NFER Publishing Company; 1978.

20. Goldberg DP, Gater R, Sartorius N, Ustun T, Piccinelli M, Gureje $\mathrm{O}$, et al. The validity of two versions of the GHQ in the WHO study of mental illness in general health care. Psychological Medicine. 1997;27(1):191-7.

21. Yusoff MSB, Rahim AFA, Yaacob M. The sensitivity, specificity and reliability of the Malay version 12-items General Health Questionnaire (GHQ-12) in detecting distressed medical students. ASEAN Journal of Psychiatry. 2010;11(1).

22. Yusoff MSB, Abdul Rahim AF, Yaacob MJ. The development and validity of the Medical Student Stressor Questionnaire (MSSQ). ASEAN Journal of Psychiatry. 2010;11(1):2315.

23. Yusoff MSB. A Confirmatory Factor Analysis Study on the Medical Student Stressor Questionnaire among Malaysian medical students. Education in Medicine Journal. 2011;3(1):e44-e55.

24. Yusoff MSB. A multicenter study on validity of the 30-items Brief COPE in identifying coping strategies among medical students. International Medical Journal. 2010;17(14):249-53.

25. Carver CS. You want to measure coping but your protocol too long: Consider the brief cope. International journal of behavioral medicine. 1997;4(1):92-100.

26. Lovibond SH, Lovibond PF. Manual for the Depression Anxiety Stress Scales. 2nd ed. Sydney: Pscyhology Foundation; 1995.

27. McDowell I. Measuring health: A guide to rating scales and questionnaires. 3rd ed. New York: Oxford University Press; 2006.

28. Barman A. Sample Size Precision and Power Calculator. 1.0 ed. Malaysia: Arunodaya Barman; 2009.

29. Kaplowitz MD, Hadlock TD, Levine R. A comparison of web and mail survey response rates. Public opinion quarterly. 2004;68(1):94101.
30. Cobanoglu C, Warde B, Moreo PJ. A comparison of mail, fax and web-based survey methods. International journal of market research. 2001;43(4):441-52.

31. Yusoff MSB, Rahim AFA, Yaacob MJ. Stress and stressors among medical students in School of Medical Sciences, Universiti Sains Malaysia: VDM Publishing House, Germany; 2011.

32. Arifin WN. Random sampling and allocation using SPSS. Education in Medicine Journal. 2012;4(1).

33. Pallant J. SPSS survival Manual - A step by step guid to data analysis using SPSS. 4th ed. Australia: Allen \& Unwin; 2011.

34. Cohen JW. Statistical power analysis for the behavioral sciences. 2nd ed. Hillsdale, NJ: Lawrence Erlbaum Associates; 1988.

35. Whitehouse W, Dinges D, Orne E, Keller S, Bates B, Bauer N, et al. Psychosocial and immune effects of self-hypnosis training for stress management throughout the first semester of medical school. Psychosomatic Medicine. 1996;58(3):249.

36. Holtzworth-Munroe A, Munroe MS, Smith RE. Effects of a stress-management training program on first-and second-year medical students. Journal of Medical Education. 1985.

37. Cohen J. Statistical power analysis for the behavioral sciences. 2nd ed. Hillsdale, NJ: Lawrence Erlbaum Associates; 1988.

38. Becker LA. Effect Size (ES)2000: Available from: http://www.uccs.edu/ faculty/lbecker/es.htm.

39. Harden RM. Innovation in medical education. 6th International Medical Education Conference; Kuala Lumpur: Internation Medical University; 2009.

40. Vitaliano PP, Maiuro RD, Russo J, Mitchell ES. Medical student distress: A longitudinal study. Journal of Nervous and Mental Disease. 1989;177(2):70-6.

41. Walkiewicz M, Tartas M, Majkowicz M, Budzinski W. Academic achievement, depression and anxiety during medical education predict the styles of success in a medical career: A 10-year longitudinal study. Medical Teacher. 2012;34(8):e611-e9.

42. Roh MS, Jeon HJ, Kim H, Han SK, Hahm BJ. The prevalence and impact of depression among medical students: a nationwide cross-sectional study in South Korea. Academic Medicine. 2010;85(8):1384-90.

43. Shapiro S, Schwartz G, Bonner G. Effects of mindfulness-based stress reduction on 
medical and premedical students. Journal of behavioral medicine. 1998;21(6):581-99.

44. Kiecolt-Glaser JK, Glaser R, Strain EC, Stout JC, Tarr KL, Holliday JE, et al. Modulation of cellular immunity in medical students. Journal of Behavioral Medicine. 1986;9(1):5-21.

45. Yusoff MSB, Esa AR. A DEAL-based intervention for the reduction of depression, denial, self-blame and academic stress: A randomized controlled trial. Journal of Taibah University Medical Sciences. in press.

46. Paluska SA, Schwenk TL. Physical activity and mental health: current concepts. Sports Medicine. 2000;29(3):167-80.

47. Van der Klink J, Blonk R, Schene AH, Van Dijk F. The benefits of interventions for work-related stress. American Journal of Public Health. 2001;91(2):270-6.

48. Jain S, Shapiro SL, Swanick S, Roesch SC, Mills PJ, Bell I, et al. A randomized controlled trial of mindfulness meditation versus relaxation training: effects on distress, positive states of mind, rumination, and distraction. Annals of Behavioral Medicine. 2007;33(1):1121.

49. Nathan RG, Nixon FE, Robinson LA, Bairnsfather L. Effects of a stress management course on grades and health of first-year medical students. Journal of Medical Education. 1987.

50. Mitchell R, Matthews J, Grandy T, Lupo $\mathrm{J}$. The question of stress among first-year medical students. Academic Medicine. 1983;58(5):367.

51. Albanese MA. Challenges in using rater judgements in medical education. Journal of evaluation in clinical practice. 2000;6(3):305-19. 52. Iglesias SL, Azzara S, Argibay JC, Arnaiz ML, de Valle Carpineta M, Granchetti H, et al. Psychological and Physiological Response of Students to Different Types of Stress Management Programs. . American Journal of Health Promotion. 2012;26(6):e149-e58.

53. Richardson KM, Rothstein HR. Effects of occupational stress management intervention programs: a meta-analysis. Journal of occupational health psychology. 2008;13(1):6993. 